Eur. J. Clin. Chem. Clin. Biochem.

Vol. 31, 1993, pp. 765-771

(C) 1993 Walter de Gruyter \& Co.

Berlin - New York

\title{
Blood Plasma Pseudouridine in Patients with Malignant Proliferative Diseases ${ }^{1}$ )
}

By T. Motyl ${ }^{1}$, Zdzislawa Traczyk ${ }^{2}$, Slawomira Cieśluk ${ }^{2}$, Dorota Daniewska-Michalska ${ }^{3}$, Wanda Kukulska ${ }^{1}$, Z. Kalużny ${ }^{2}$, Malgorzata Podgurniak ${ }^{1}$, A. Orzechowski ${ }^{1}$ and B. Dęski ${ }^{4}$

${ }^{1}$ Department of Animal Physiology, Faculty of Veterinary Medicine, Warsaw Agricultural University, Warsaw, Poland

${ }^{2}$ IVth Division of Internal Medicine, Central Clinical Hospital, Warsaw, Poland

${ }^{3}$ Department of Internal Medicine, Central Hospital of Medical School, Warsaw, Poland

${ }^{4}$ Department of Biochemistry, Faculty of Veterinary Medicine, Warsaw Agricultural University, Warsaw, Poland

(Received March 2/July 8, 1993)

Summary: The blood plasma concentration of pseudouridine was estimated in 104 healthy adult subjects, and 108 patients suffering from malignant proliferative diseases. The HPLC method for simultaneous determination of pseudouridine and creatinine was applied.

The average physiological concentraticn of pseudouridine in blood plasma was $2.43 \pm 0.97 \mu \mathrm{mol} \cdot 1^{-1}$ or $29.15 \pm 7.40 \mathrm{mmol} \cdot \mathrm{mol}^{-1}$ creatinine. The physiological urinary excretion of pseudouridine was $14.32 \pm 5.20$ $\mu \mathrm{mol} \cdot 24 \mathrm{~h}^{-1} \cdot \mathrm{kg}^{-0.75}$ or $19.60 \pm 5.22 \mathrm{mmol} \cdot \mathrm{mol}^{-1}$ creatinine. Renal clearance of pseudouridine and endogenous creatinine were $4.04 \pm 0.99$ and $5.50 \pm 1.46 \mathrm{ml} \cdot \mathrm{kg}^{-0.75}$, respectively. A positive correlation ( $\mathrm{r}=0.55, \mathrm{P}<0.01$ ) was found between age (in the range 20-92 years) and blood plasma pseudouridine concentration $\left(\mu \mathrm{mol} \cdot 1^{-1}\right)$. By expressing plasma pseudouridine in relation to plasma creatinine, the apparent influence of non-metabolic factors (age, renal insufficiency, blood dilution) on the plasma pseudouridine concentration were largely excluded.

Among haematological proliferative diseases the highest values of plasma pseudouridine concentrations were observed in chronic lymphocytic leukaemia $\left(8.19 \mu \mathrm{mol} \cdot 1^{-1} ; 54.9 \mathrm{mmol} \cdot \mathrm{mol}^{-1}\right.$ creatinine) and multiple myeloma $\left(7.02 \mu \mathrm{mol} \cdot 1^{-1} ; 52.5 \mathrm{mmol} \cdot \mathrm{mol}^{-1}\right.$ creatinine). In multiple myeloma, but not in chronic lymphocytic leukaemia, the plasma pseudouridine concentration depended on the clinical stage. A lower, but still significant response in non-Hodgkin's lymphoma was noted $\left(4.03 \mu \mathrm{mol} \cdot 1^{-1} ; 40.88 \mathrm{mmol} \cdot \mathrm{mol}^{-1}\right.$ creatinine).

A significant increase of the plasma pseudouridine concentration was characteristic of adenocarcinomas of the large intestine, and it occurred in the early stages of malignant growth. In patients with lung cancer the plasma pseudouridine concentration was elevated only in advanced cases with metastases. The increased pseudouridine concentration was evident in all examined cancers of the urogenital system: cancer of the urinary bladder, cancer of the kidney, cancer of the prostate, and cancer of the testis.

It is concluded that the determination of pseudouridine in blood plasma, particularly in relation to creatinine, is a valuable biochemical marker of accelerated turnover rate of nucleic acids associated with neoplastic growth.

') This study was supported by a grant from the Ministry of National Education. 


\section{Introduction}

Malignant growth is accompanied by a rapid turnover of nucleic acids. Nucleic acid turnover may be evaluated by measuring its synthesis as well as degradation rate. RNA molecules contain both nucleosides and modified nucleosides formed post-transcriptionally by the action of modifying enzymes. In contrast to nucleosides, most of the modified RNA catabolites are not reutilized in nucleotide synthesis by salvage pathways, nor are they further degraded. Modified nucleosides released from RNA molecules in the cell appear in extracellular fluid, as well as blood plasma, and they are excreted in urine, some of them quantitatively $(1,2)$. The measurement of urinary excretion of pseudouridine, 7-methylguanine, and $\mathrm{N}^{2}, \mathrm{~N}^{2}$-dimethyl-guanosine was used to assess whole-body turnover of rRNA, mRNA, and tRNA in preterm infants and adults $(3,4)$. Pseudouridine is generally excreted in concentrations of 10 to 100 times that of other nucleosides, both in healthy subjects and cancer patients $(5,6)$. The source of pseudouridine detected in urine is whole-body catabolism of tRNA and rRNA $(3,4)$. Among several modified nucleosides tested, pseudouridine is the compound of choice for investigation in the follow up of neoplastic disease (5). There is a considerable number of publications concerning changes in urinary pseudouridine excretion as a response to malignant growth $(6-14)$. There is much less information about changes in blood plasma concentrations of pseudouridine, which is 100 times lower than in urine, although it can still be determined precisely with HPLC techniques (15-18). Advantages of pseudouridine as a marker of RNA turnover rate in comparison with other modified nu-

Tab. 1. Patients with haematological neoplasms and cancers.

\begin{tabular}{lc}
\hline Diagnosis & $\begin{array}{l}\text { Number } \\
\text { of patients }\end{array}$ \\
\hline Haematological proliferative diseases: & \\
chronic lymphocytic leukaemia & 17 \\
multiple myeloma & 10 \\
other non-Hodgkin's lymphomas & 12 \\
Hodgkin's disease & 6 \\
Carcinomas: & \\
lung & 12 \\
gaster & 8 \\
pancreas & 5 \\
gallbladder & 3 \\
colon & 7 \\
rectum & 11 \\
kidney & 6 \\
prostate & 3 \\
urinary bladder & 5 \\
testis & 3 \\
\hline
\end{tabular}

cleosides are its approximately 100 -fold greater concentration in blood plasma, and its lesser variability attributable to the renal clearance rate, sex-related differences, genetic influences or environmental conditions (19). There are only a few reports indicating the elevation of serum pseudouridine concentrations in patients suffering from neoplastic diseases $(5,17$, 20, 21).

The present experiment was undertaken to extend the above studies and to estimate blood plasma pseudouridine concentrations in adult healthy subjects of variable age and sex, and patients suffering from malignant proliferative diseases.

\section{Materials and Methods}

Patients

Observations were performed on 212 individuals. The control group consisted of 104 healthy volunteers ( 72 male and 32 female) aged between 20 and 92 . The groups with haematological neoplasms and cancers consisted of 45 and 63 patients, respectively (tab. 1).

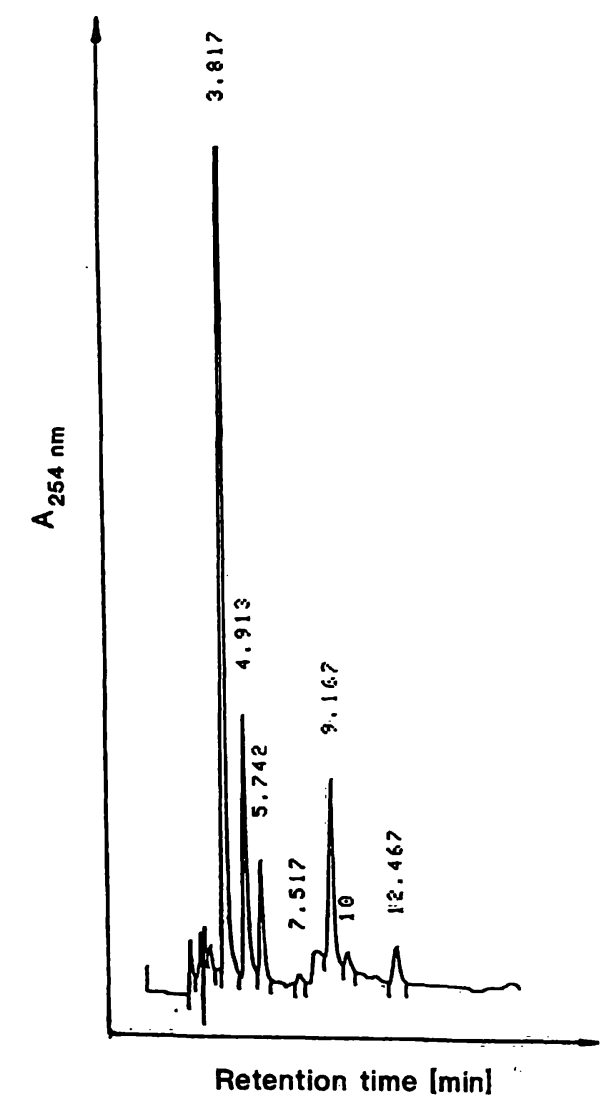

Fig. 1. HPLC chromatogram of purines and pyrimidines in blood plasma of a patient with adenocarcinoma of the sigmoid, and metastases in the urinary bladder. Compounds: $3.8 \mathrm{~min}$ - uric acid; $4.9 \mathrm{~min}$ - creatinine, 5.7 min - pseudouridine, $9.1 \mathrm{~min} \mathrm{-} \mathrm{hypoxanthine,} 10 \mathrm{~min}$ - xanthine, $12.4 \mathrm{~min}$ - uridine. 
Sample preparation and analytical procedure

Peripheral blood $(2 \mathrm{ml})$ was drawn into a heparinized syringe prior to the morning meal. Immediately after sampling, whole blood was centrifuged at $2500 \mathrm{~g}$ for $10 \mathrm{~min}$ at $4{ }^{\circ} \mathrm{C}$. Two volumes of ice-cold fresh trichloroacetic acid solution $(80 \mathrm{~g} / \mathrm{l})$ were added to the blood plasma, and the resulting precipitate removed by centrifugation. The supernatant was then extracted three times with 1.5 volumes of water-saturated diethyl ether to remove the trichloroacetic acid. The aqueous layer was passed through a $0.45 \mu \mathrm{m}$ Millipore filter prior to analysis.

In order to calculate the rate of urinary pseudouridine excretion and the renal clearance of this nucleoside under physiological conditions, twenty-four hour collection of urine was performed in 30 healthy individuals. Urine samples were purified using $\mathrm{C}_{18}$ SEP-PAK Waters Associates cartridges.

Pseudouridine and creatinine concentrations were determined according to the method described by Simmonds \& Harkness (16). High performance liquid chromatography (HPLC) was performed with an isocratic liquid chromatograph "Beckman 330 " using an ultrasphere Altex column ODS $5 \mu \mathrm{m}, 4.6 \cdot 250$ $\mathrm{mm}, \mathrm{RP}-18$ cartridge precolumn $(4.6 \cdot 30 \mathrm{~mm})$ and RP-18 guard cartridge $(3.2 \cdot 15 \mathrm{~mm})$ - Pierce. The absorbance was measured by a UV detector "Beckman 153" equipped with a $254 \mathrm{~nm}$ filter. For registration and integration of results, an integratorrecorder "Shimadzu R-R3A" was used. The mobile phase was $0.01 \mathrm{~mol} \cdot 1^{-1}$ potassium dihydrogen phosphate $(\mathrm{pH}$ 5.9) containing $10 \mathrm{ml} / 1$ methanol, at a flow rate of $1 \mathrm{ml} \cdot \mathrm{min}^{-1}$. An example of the blood plasma chromatogram of purine and pyrimidine compounds is presented in figure 1.

\section{Statistical analysis}

All data were stored in a database using a dBase3p programme, then transferred to a STATGRAPH program for graphic and statistical evaluation.

\section{Results}

The relationship between age and plasma pseudouridine concentration in 104 healthy adults is presented in figure 2. There was a statistically significant positive correlation between age (in the range of 20 and 92 years of age) and pseudouridine concentration in blood plasma $\left(\mu \mathrm{mol} \cdot 1^{-1}\right)$. The average pseudouridine concentration in both males and females was 2.35 and $2.61 \mu \mathrm{mol} \cdot 1^{-1}$ (differences non-significant), at the average ages of 30 and 58, respectively. The correla-

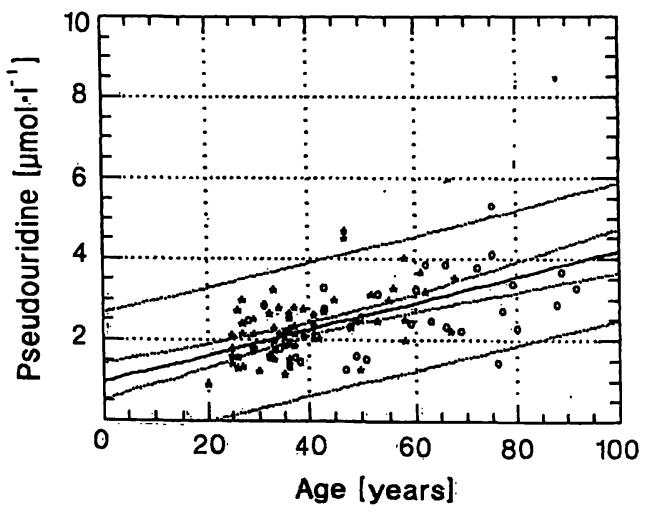

Fig. 2. The relationship between age and blood plasma pseudouridine concentration $\left(\mu \mathrm{mol} \cdot 1^{-1}\right)$ in 104 healthy adults; $\mathrm{r}=0.55, \mathrm{P} \leq 0.01 ; 0-$ female, $*-$ male
Tab. 2. Blood plasma and urinary pseudouridine concentration in healthy subjects.

\begin{tabular}{|c|c|c|}
\hline Quantity & $\mathrm{n}$ & Mean $\pm S D$ \\
\hline \multicolumn{3}{|l|}{$\begin{array}{l}\text { Blood plasma pseudouridine } \\
\text { concentration }\end{array}$} \\
\hline $\begin{array}{l}\mu \mathrm{mol} \cdot \mathrm{I}^{-1} \\
\mathrm{mmol} \cdot \mathrm{mol}^{-1} \text { creatinine }\end{array}$ & $\begin{array}{l}104 \\
104\end{array}$ & $\begin{array}{r}2.43 \pm 0.97 \\
29.15 \pm 7.40\end{array}$ \\
\hline $\begin{array}{l}\text { Urinary pseudouridine excr } \\
\mu \mathrm{mol} \cdot 24 \mathrm{~h} \cdot \mathrm{kg}^{-0.75} \\
\mathrm{mmol} \cdot \mathrm{mol}^{-1} \mathrm{creatinine}\end{array}$ & $\begin{array}{l}30 \\
30\end{array}$ & $\begin{array}{l}14.32 \pm 5.20 \\
19.60 \pm 5.22\end{array}$ \\
\hline $\begin{array}{l}\text { Renal pseudouridine cleara } \\
\mathrm{ml} \cdot \mathrm{min}^{-1} \cdot \mathrm{kg}^{-0.75}\end{array}$ & 30 & $4.04 \pm 0.99$ \\
\hline $\begin{array}{l}\text { Renal creatinine clearance* } \\
\mathrm{ml} \cdot \mathrm{min}^{-1} \cdot \mathrm{kg}^{-0.75}\end{array}$ & 30 & $5.50 \pm 1.46$ \\
\hline
\end{tabular}

* glomerular filtration rate

tion coefficient of age vs pseudouridine was lowered $(r=0.26)$ when pseudouridine concentration was calculated per unit of plasma creatinine $\left(\mathrm{mmol} \cdot \mathrm{mol}^{-1}\right.$ creatinine).

Average values of plasma pseudouridine concentration, rate of urinary excretion and renal clearance of pseudouridine under physiological conditions are presented in table 2 . The ratio of pseudouridine to creatinine was higher in blood plasma than in urine, which is consistent with lower values of renal pseudouridine clearance when compared with clearance of endogenous creatinine.

Among lymphoproliferative diseases the highest values of blood plasma pseudouridine concentrations were observed in chronic lymphocytic leukaemia (8.19 $\mu \mathrm{mol} \cdot 1^{-1} ; 54.9 \mathrm{mmol} \cdot \mathrm{mol}^{-1}$ creatinine) and multiple myeloma $\left(7.02 \mu \mathrm{mol} \cdot 1^{-1} ; 52.2 \mathrm{mmol} \cdot \mathrm{mol}^{-1}\right.$ creatinine) (fig. 3). The concentration of pseudouridine in

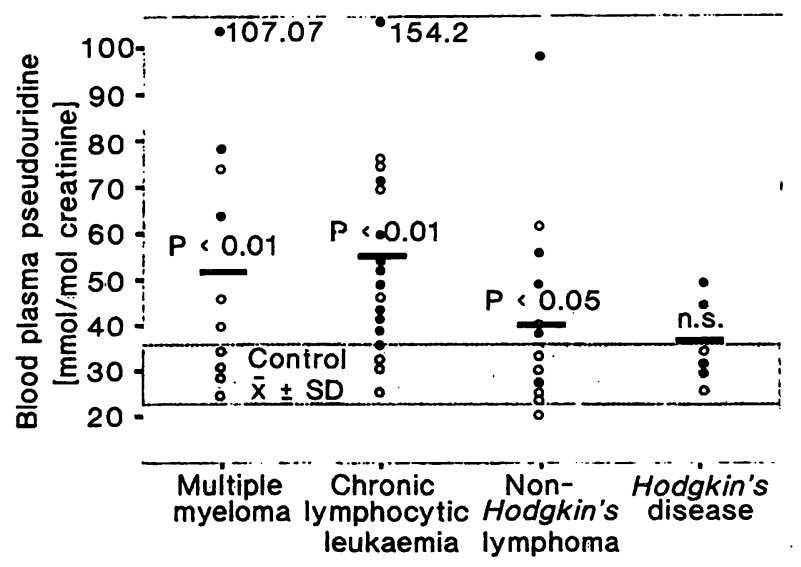

Fig. 3. Blood plasma concentration of pseudouridine in patients with haematological proliferative diseases in early (open circles) and advanced (closed circles) stages. Advanced stages are considered as: stage III in multiple myeloma (23), stages II, III, IV in chronic lymphocytic leukaemia (22), stages III, IV in non-Hodgkin's lymphoma (24), stages III, IV in Hodgkin's disease (24). 
the plasma of patients with chronic lymphocytic leukaemia was independent of the stage of the disease, i. e. it was elevated to the same extent both in early stages $(0$, I) and advanced stages (II, III, and IV) of leukaemia (clinical classification according to Rai et al. (22)). In the case of multiple myeloma the lowest concentration of pseudouridine was observed in 2 patients with remission and 2 patients with stage $I_{A}$, but the highest concentration was in 3 patients with stage $\mathrm{III}_{\mathrm{B}}$ (clinical classification according to Durie \& Salmon (23)). Non-Hodgkin's lymphoma was responsible for a significant increase of the mean plasma pseudouridine concentration $\left(4.03 \mu \mathrm{mol} \cdot 1^{-1} 40.88\right.$ $\mathrm{mmol} \cdot \mathrm{mol}^{-1}$ creatinine) which was seen only in advanced cases (stage III and IV - according to Ann Arbor clinical staging classification (24)). No significant response was observed in patients with Hodgkin's disease $\left(3.08 \mu \mathrm{mol} \cdot 1^{-1} ; 36.4 \mathrm{mmol} \cdot \mathrm{mol}^{-1}\right.$ creatinine).

In all examined cancers average values were significantly higher compared with that of the control (tab. 3).

Tab. 3. Average $\pm \mathrm{SD}$ blood plasma concentration of pseudouridine in cancer patients.

\begin{tabular}{|c|c|c|}
\hline \multirow[t]{2}{*}{ Carcinoma } & \multicolumn{2}{|l|}{ Pseudouridine } \\
\hline & $\mu \mathrm{mol} \cdot 1^{-1}$ & $\begin{array}{l}\mathrm{mmol} \cdot \mathrm{mol}^{-1} \\
\text { creatinine }\end{array}$ \\
\hline Lung & $5.17 \pm 4.13^{* *}$ & $49.8 \pm 29.6^{* *}$ \\
\hline Gaster & $4.39 \pm 3.01 * *$ & $35.4 \pm 7.9^{*}$ \\
\hline Pancreas & $2.75 \pm 0.69$ & $38.4 \pm 10.4^{* *}$ \\
\hline Gallbladder & $3.79 \pm 0.75^{*}$ & $63.5 \pm 59.7 * *$ \\
\hline Colon & $6.46 \pm 9.08 * *$ & $38.8 \pm 19.31 * *$ \\
\hline Rectum & $4.24 \pm 1.88^{* *}$ & $50.5 \pm 18.3^{* *}$ \\
\hline Kidney & $6.85 \pm 2.42^{* *}$ & $\pm 14.8^{* *}$ \\
\hline Prostate & $4.77 \pm 1.06^{* *}$ & $\pm \quad 4.2 * *$ \\
\hline Urinary bladder & $14.9 \pm 17.1^{* *}$ & $\pm 36.4^{* *}$ \\
\hline Testis & $16.71 \pm 24.1^{* *}$ & $108.8 \pm 138.8 * *$ \\
\hline Control & $2.43 \pm 0.97$ & $29.15 \pm$ \\
\hline
\end{tabular}

$* P \leq 0.05$

$* * \mathrm{P} \leq 0.01$

The relationship between the expansion of examined lung, gastric, and large intestine cancers and plasma pseudouridine concentrations is presented in figure 4. In the case of large intestine cancer (adenocarcinoma of the colon and adenocarcinoma of the rectum) only three patients (two with primary focus and one with dissemination) had plasma pseudouridine concentrations within control values (mean $\pm S D$ ). In patients with lung cancer an evident increase of plasma pseudouridine concentrations was seen only during dissemination. A relatively low response, independent of disease progression, was observed in patients with gastric adenocarcinoma (fig. 4).

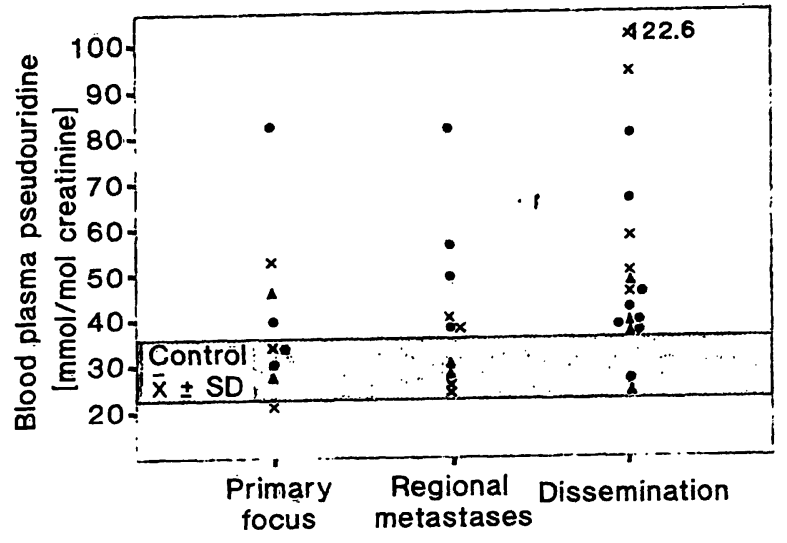

Fig. 4. The relationship between expansion of malignant growth and blood plasma pseudouridine concentration in patients with carcinoma of the lung $x$, carcinoma of the gaster $\boldsymbol{\Delta}$, and carconima of large intestine $\bullet$.

\section{Discussion}

The mean physiological concentration of pseudouridine in blood plasma (tab. 2) is similar to that observed in serum by Russo et al. (17) $\left(2.48 \mu \mathrm{mol} \cdot \mathrm{i}^{-1}\right)$ and by Topp et al. (25) $\left(2.76 \mu \mathrm{mol} \cdot 1^{-1}\right)$. A significant positive correlation between the age of healthy adults and plasma pseudouridine concentration was found (fig. 2). A similar relationship was observed by Tritsch et al. (26) for urinary pseudouridine concentrations, rising by $5.9 \mathrm{mmol} \cdot \mathrm{mol}^{-1}$ creatinine per decade. A comparative analysis of serum pseudouridine concentration, performed by Salvatore et al. (27) indicates that practically all the data collected with the various procedures agree within quite narrow limits. Rising plasma pseudouridine concentrations in healthy adults in our studies (fig. 2) may reflect an age-related increase in the catabolism of whole-body rRNA + tRNA and/or renal insufficiency. The advantage of the applied HPLC method is a simultaneous determination of pseudouridine and creatinine (fig. 1), and thus the possibility of a direct calculation of plasma pseudouridine in relation to the creatinine concentrations. Such an expression of the pseudouridine concentration takes into account changes in dilution of blood plasma resulting from an increased or decreased supply of water (e.g. absorption from the gastrointestinal tract, parenteral infusions) and impaired kidney function. Our recent study (28) showed that pseudouridine accumulates markedly in blood plasma (25 times higher concentration than physiological) in patients with chronic renal failure. Among examined purines and pyrimidines, pseudouridine had the lowest efficiency of haemodialysis (44\%) and the longest $t_{1 / 2}$ (relative to creatinine) in plasma. In the present study, calculation of plasma pseudouridine in relation to creatinine concentration largely 
abolished the variability of pseudouridine with age. According to Salvatore et al. (27) the serum "pseudouridine index" (pseudouridine: creatinine ratio) almost equalled the reference pseudouridine values for normal subjects. In healthy subjects renal pseudouridine clearance is lower than clearance of endogenous creatinine (tab. 2), which indicates that pseudouridine can be partially reabsorbed in renal tubules. The ratio of pseudouridine vs. creatinine in blood plasma to that in urine (1.48) was comparable to that reported by Topp et al. (25). The method described by Kuo et al. (15) allowed the separation and quantification of other modified nucleosides in serum using reversedphase HPLC with diode-array measurement. The concentrations of other nucleosides in blood serum are also consistently elevated in patients with malignant proliferative diseases $(15,29)$, but it should be noted that their blood plasma concentrations are 100 times less than that of pseudouridine, and their concentrations also display greater variability, due to nonmetabolic factors (19).

The relative independence of plasma pseudouridine concentrations on non-metabolic factors, when calculated per unit of creatinine, encouraged us to use this form of pseudouridine expression in neoplastic cases. In general, results of pseudouridine concentration in blood plasma expressed in absolute values $\left(\mu \mathrm{mol} \cdot 1^{-1}\right)$ correlate $(r=0.51)$ with relative values ( $\mathrm{mmol} \cdot \mathrm{mol}^{-1}$ creatinine), but not in all examined patients. Among haematological neoplasms the highest concentration of pseudouridine was observed in the plasma of patients suffering from multiple myeloma and chronic lymphocytic leukaemia (fig. 3). This is in agreement with the findings of Sorensen et al. (6), who demonstrated that urinary pseudouridine excretion in multiple myeloma usually exceeds that in other neoplasms, and there is a highly significant linear trend towards a negative prognosis with a rising concentration of urinary pseudouridine. It is interesting that in mice carrying a transplantable myeloma tumour no increase in the serum pseudouridine concentration was seen, despite the presence of a considerable tumour burden (30). Our results indicate that the plasma pseudouridine concentration in patients with multiple myeloma depends on tumour mass, since the lowest concentration of this modified nucleoside was observed in remisssion and stage $I_{A}$, and the highest in stage $\mathrm{III}_{B}$ of the disease (fig. 3).

There are several reports indicating increased urinary pseudouridine excretion in children and adults with different types of leukaemia $(8-11,31,32)$. We could found no corresponding literature data for blood plasma pseudouridine concentrations in chronic lymphocytic leukaemia. A single literature source (27) reports that serum pseudouridine concentrations in three patients with chronic lymphocytic leukaemia ranged from 10.64 to $31.37 \mu \mathrm{mol} \cdot 1^{-1}$. In contrast to multiple myeloma, the plasma pseudouridine concentration in chronic lymphocytic leukaemia does not seem to be dependent on disease progression (fig. 3). A considerable increase of the pseudouridine concentration was observed both in early and advanced stages of leukaemia. We suppose that the plasma pseudouridine concentration might reflect proliferative activity of lymphoidal cells. However, a greater number of cases should be examined, in order to distinguish between various types of chronic lymphocytic leukaemia, characterized by more or less active proliferation. It is interesting that chronic lymphocytic leukaemia leads to a generally higher concentration of pseudouridine in blood plasma than non-Hodgkin's lymphoma, in spite of the clinically less dynamic progression of the disease. Our recent studies demonstrated a significant increase in urinary pseudouridine excretion in patients with multiple myeloma, chronic lymphocytic leukaemia and non-Hodgkin's lymphoma, without significant changes in Hodgkin's disease and polycythaemia vera (33).

Rapid turnover of rRNA + tRNA is characteristic of certain cancers of the gastrointestinal tract, especially large intestine adenocarcinomas.

However, in these cases the plasma pseudouridine concentration was independent in disease progression, since elevated concentrations of pseudouridine in plasma were observed both in patients with early and advances stages (fig. 4). A relatively low response was observed in patients suffering from gastric and pancreatic adenocarcinoma. It is interesting that gastric adenocarcinoma, in contrast to other cancers of the gastrointestinal tract (e. g. large intestine adenocarcinomas), did not affect urinary pseudouridine excretion independently of the stage of the disease (33). In patients with lung cancer, the plasma pseudouridine concentration seems to be dependent on dissemination of the disease, and it increased in advanced cases with metastases (fig. 4). The elevation of plasma pseudouridine concentration leads to increased urinary pseudouridine excretion in patients with lung cancer (33). McEntire et al. (21) showed that precise measurement of an array of 29 nucleosides in serum with subsequent data modelling may provide a clinically useful approach to patient classification in diagnosis of lung cancer and subsequent therapeutic monitoring. The elevated plasma pseudouridine concentration was also evident in all examined cases of cancer of the urogenital system: cancer of the urinary bladder, cancer of the kidney, cancer of the prostate, and cancer of the testis. Recently, Rasmuson et al. (34) 
demonstrated that increased urinary pseudouridine excretion can be an independent prognostic factor in renal cell carcinoma. The concentration of pseudouridine correlated to tumour grade and tumour size. Survival time was also significantly reduced in patients with increased pseudouridine excretion.

In conclusion, we can say that the determination of pseudouridine in blood plasma, particularly in relation to creatinine, is a valuable biochemical marker of accelerated turnover rate of nucleic acids associated with neoplastic growth. The most evident response in blood plasma pseudouridine concentrations, noticed in early stages of malignant growth, is characteristic of patients with chronic lymphocytic leukaemia and large intestine cancers.

\section{Acknowledgement}

The authors wish to thank Dr. Roman Dorociak for permission to study his patients, and Mrs. Teresa Hass for skilful technical assistance.

\section{References}

1. Weissman, S., Eisen, A. Z., Lewis, M. \& Karon, M. (1962) Pseudouridine metabolism. III Studies with isotopically labelled pseudouridine. J. Lab. Clin. Med. 60, 40-47.

2. Craddock, V. M., Mattocks, A. R. \& Magge, P. N. (1968) The fate of $7-\left[{ }^{14} \mathrm{C}\right]$ methylguanine after administration to the rat. Biochem. J. 109, 75-78.

3. Sander, G., Topp, H., Heller-Schöch, G., Wieland, J. \& Schöch, G. (1986) Ribonucleic acid turnover in man: RNA catabolites in urine as measure for the metabolism of each of three major species of RNA. Clin. Sci. 71, 367-374.

4. Sander, G., Hulsemann, J., Topp, H., Heller-Schöch, G. \& Schöch, G. (1986) Protein and RNA turnover in preterm infants and adults: A comparison based on urinary excretion of 3-methylhistidine and modified one-way RNA catabolites. Ann. Nutr. Metab. 30, 137-142.

5. Salvatore, F., Colonna, A., Costanzo, F., Russo, T., Esposito, F. \& Cimino, F. (1983) Modified nucleosides in body fluids of tumor-bearing patients. Recent Results Cancer Res. 84, 360-377.

6. Sorensen SH, Brown, D. A., Cooper, E. H., Kelly, K. A. \& Mac Lennan, I. C. M. (1985) Urinary pseudouridine excretion in myelomatosis. Br. J. Cancer 52, 863-866.

7. Borek, E., Sharma, O. K. \& Waalkes, T. P. (1983) New applications of urinary nucleoside markers. Recent Results Cancer Res. 84, $301-316$.

8. Heldman, D. A., Grever, M. R. \& Trewyn, R. W. (1983) Differential excretion of modyfied nucleosides in adult acute leukemia. Blood 61, 291-295.

9. Heldman, D. A., Grever, M. R., Miser, J. S. \& Trewyn, R. W. (1983) Relationship of urinary excretion of modyfied nucleosides to disease status in childhood lymphoblastic leukemia. J. Natl. Cancer Inst. 71, 269-273.

10. Heldman, D. A., Grever, H. R., Spreicher, C. E. \& Trewyn, R. W. (1983) Urinary excretion of modified nucleosides in chronic myelogenous leukemia. J. Lab. Clin. Med. 101, $783-792$.

11. Nielsen, H. R. \& Killman, S.-A. (1983) Urinary excretion of $\beta$-aminosobutyrate and pseudouridine in acute and chronic myeloid leukemia. J. Natl. Cancer Inst. 71, 887891.

12. Rasmuson, R. \& Björk, G. R. (1985) Excretion of pseudouridine in urine as a marker in malignant diseases. Bull. Mol. Med. 10, 143-154.

13. Dieckhues, B. (1986) Identification of pathologic metabolic metabolites of melanin and melatonin metabolism in urine of patients with malignant melanoma of the choroid by means of high-pressure liquid chromatography (HPLC). Klin. Mbl. Augenheilk. 189, 34-35 (Ger).

14. Tamura, S., Amuro, Y., Nakano, T., Fuji, J., Moriwaki, Y., Yamamoto, T., Hada, T. \& Higashino, K. (1986) Urinary excretion of pseudouridine in patients with hepatocellular carcinoma. Cancer 57, 1571-1575.
15. Kuo, K. C., Phan, D. T., Williams, N. \& Gehrke, C. W. (1990) Ribonucleosides in biological fluids by a high-resolution RPLC-UV method. In: Chromatography and Modification of Nucleosides (Gehrke, C. W. \& Kuo, K. C. T., eds) Journal of Chromatography Library 45C, pp. 41C113C. Elsevier, 1990.

16. Simmonds, R. J. \& Harkness, R. A. (1981) High-performance liquid chromatographic methods for base and nucleoside analysis in extracellular fluids and in cells. J. Chrömatogr. 226, 369-381.

17. Russo, T., Colonna, A., Esposito, F., Salvatore, F. \& Cimino, F. (1982) Detection and estimation of several modified nucleosides in serum of cancer patients. Italian J. Biochem. $31,75-78$.

18. Topp, H., Sander, G., Heller-Schöch, G. \& Schöch, G. (1985) A high-performance liquid chromatographic method for the determination of pseudouridine and uric acid in native human urine and ultrafiltered serum. Anal. Biochem. $150,353-358$

19. Pane, F., Oriani, G., Kuo, K. C. T., Gehrke, C., Salvatore, F. \& Sacchetti, L. (1992) Reference intervals of eight modified nucleosides in serum in healthy population from Italy and the United States. Clin. Chem. 38, 671-677.

20. Salvatore, F., Russo, T., Colonna, A., Cimino, L., Mazzacca, G. \& Cimino, F. (1983) Pseudouridine determination in blood serum as tumor marker. Cancer Detect. Prev. 6, $531-536$.

21. McEntire, J. E., Kuo, K. C., Smith, M. E., Stalling, D. I., Richens jr, J. W., Zumwalt, R. W., Gehrke, C. W. \& Papermaster, B. W. (1990) Serum nucleoside chromatography for classification of lung cancer and controls. In: Chromatography and Modification of Nucleosides (Gehrke, C. W. \& Kuo, K. C. T., eds) Journal of Chromatography Library 45C, pp. 367-387. Elsevier, 1990.

22. Rai, K., Sawitsky, A., Cronkite, E., Chanana, A., Lewy, R. N. \& Pasternack, B. S. (1975) Clinical staging of chronic lymphocytic leukemia. Blood 46, 219.

23. Durie, B. G. M. \& Salmon, S. E. (1975) A clinical staging system for multiple myeloma; correlation of measured myeloma cell mass with presenting clinical features, response to treatment and survival. Cancer 36,842 .

24. Carbone, P., Kaplan, H. S., Musshoff, K., Smithers, D. W. \& Tubiana, M. (1971) Report of the committee on Hodgkin's staging classification. Cancer Res. 31, 1860.

25. Topp, H., Sander, G., Heller-Schöch, G. \& Schöch, G. (1987) Determination of 7-methylguanine, $\mathrm{N}^{2}, \mathrm{~N}^{2}$-dimethylguanosine, and pseudouridine in ultrafiltered serum of healthy adults by high performance liquid chromatography. Anal. Biochem. 161, 49-56.

26. Tritsch, G. L., Luch, J. H., Evans, J. T. \& Hittelman, A. (1979) Age dependence of human urinary pseudouridine excretion. Biochem. Med. 22, 387-400. 
27. Salvatore, F., Sacchetti, L., Savoia, M., Pane, F., Russo, T., Colonna, A. \& Cimino, F. (1990) Modified nucleosides in human blood serum as biochemical signals for neoplasia. In: Chromatography and Modification of Nucleosides (Gehrke, C.W. \& Kuo, K. C. T., eds) Journal of Chromatography Library 45C, pp. 251-278. Elsevier, 1990.

28. Daniewska-Michalska, D., Motyl, T., Gellert, R., Kukulska, W., Podgurniak, M., Opechowska-Pacocha, E. \& Ostrowski, K. (1993) Efficiency of hemodialysis of pyrimidine compounds in patients with chronic renal failure. Nephron 64, 193-197.

29. Mitchell, E. P., Evans, L., Schultz, P., Madsen, R., Yarbro, J., Gehrke, C. W. \& Kuo, K. (1992) Modified nucleosides in human serum. J. Chromatogr. 581, 31-40.

30. Russo, T., Colonna, A., Salvatore, F., Cimino, F., Bridges, S. \& Gurgo, C. (1984) Serum pseudouridine as a biochemical marker in the development of AKR mouse lymphoma. Cancer Res. 44, 2567-2570.
31. Van Gennip, A. H., Van Bree-Blom, E. J., Abeling, N. G. G. M., Van Erveb, A. J. \& Voute, P. A. (1987) $\beta$-Aminoisobutyric acid as a marker of thymine catabolism in malignancy. Clin. Chim. Acta 165, 365-377.

32. Graf, N., Bach, K., Frisch, B., Haas, H. J. \& Sitzmann, F. C. (1989) The clinical value of urinary excretion of pseudouridine in infancy and childhood. Klin. Padiatr. 201, 154-162 (Ger).

33. Motyl, T., Traczyk, Z., Holska, W., Daniewska-Michalska, D., Cieśluk, S., Kukulska, W., Kałuźny, Z. \& Podgurniak, M. (1993) Comparison of urinary neopterin and pseudouridine in patients with malignant proliferative diseases. Eur. J. Clin. Chem. Clin. Biochem. 31, 205-209.

34. Rasmuson, T., Björk, G. R., Hietala S.-O., Stenling, R. \& Ljunberg, B. (1991) Excretion of pseudouridine as an independent prognostic factor in renal carcinoma. Acta Oncologica $30,11-15$.

Prof. Dr. Tomasz Motyl

Department of Animal Physiology

Faculty of Veterinary Medicine

Warsaw Agricultural University

ul. Nowoursynowska 166

PL-02-766 Warszawa

Poland 
